ORIGINAL PAPER

\title{
CD11C-AND CD123-POSITIVE DENDRITIC CELLS \\ IN DEVELOPMENT OF ANTITUMOUR IMMUNITY IN NON-SMALL CELL LUNG CANCER PATIENTS
}

\author{
Plamen Minkov $^{1}$, Maya Gulubova $^{1}$, Koni Ivanova $^{1}$, Evelin Obretenov ${ }^{2}$, Julian Ananiev ${ }^{1}$
}

${ }^{1}$ Department of General and Clinical Pathology, Medical Faculty, Trakia University, Stara Zagora, Bulgaria

${ }^{2}$ Department of Thoracic Surgery, Medical Faculty, Trakia University, Stara Zagora, Bulgaria

\begin{abstract}
Our aim was to analyzed the significance of $\mathrm{CD} 11 \mathrm{c}$ and $\mathrm{CD} 123$ positive DCs and their relations with some clinical and pathologic parameters of patients with nonsmall cell lung cancer (NSCLC).

The immunohistochemical expression of $\mathrm{CD} 11 \mathrm{c}$ and $\mathrm{CD} 123$, was evaluated in 40 patients with NSCLC.

After analysis we found that $35.3 \%$ of the patients in the T3-4 tumour stage had a high CD11c infiltration in the tumour stroma, while $100 \%$ of the patients in the T1-2 tumour stage had low infiltration $(\mathrm{p}=0.03)$. We also found that $71.4 \%$ of patients in the M1 stage had a high infiltration with CD123 in the tumour stroma, whereas only $15.6 \%$ of patients without metastases had high infiltration, analogous data are also found in comparing the distribution of CD123 in the tumour border $(\mathrm{p}=0.002$ or $\mathrm{p}=0.002)$. Comparing the density of CD123 in the border of lymph node involvement, we found that only $7.14 \%$ of patients without metastases had low infiltration with dendritic cells, whereas in patients with metastatic lymph nodes that percentage was $41.7 \%(\mathrm{p}=0.008)$.

In conclusion results suggest that CD11c- and CD123-positive DCs play an important role in antitumour immunity and can be predictive factor for tumour development in patients with NSCLC.
\end{abstract}

Key words: NSCLC, dendritic cells, CD11c, CD123.

\section{Introduction}

Lung cancer is the most frequent reason for cancer associated death. In most of $85 \%$ of the cases it is non-small cell lung cancer (NSCLC) [1]. Many factors, as well as genetic, environmental, from the micro environment and anti-cancer immunity influence the development and progression of NSCLC. In some cases, key moment in the oncogenesis is the inability of the immune system to ensure defence against cancer. The escape of anti-cancer immune response is an important component of the cancer progressing process. In the recent years, it has been clarified that the dendritic cells (DC) take central place in these mechanisms of immune system escape [2]. The tumorigenic process has eight very characteristic features: self-production of growth factors, insensibility for growth factors inhibitors, escape from apoptosis, unlimited proliferation, neo-angiogenesis, metastasis, reprograming the metabolism and escape from the immune system [3, 4].

The tumorigenic progression and development is possible because of different mechanisms that cause anticancer immune response escape and induction of immune tolerance. This is achieved by inhibition of the antigen presentation and active development 
of immune suppressing cells [5, 6]. Different types of immune cells participate in infiltration into tumorigenic tissue [7]. The infiltration of immune cells into tumorigenic tissue is associated with both good and also poor prognosis [7]. It is known, for a long time, that the degree of immune cells inclusions into tumorigenic microenvironment and in the tumour could be used as predictive marker for determination of the cancer prognosis [8]. The anti-cancer immune response is highly dependable on the capabilities of the antigen presenting cells.

Dendritic cells are the most potent antigen presenting cells. Under some stimuluses the immature DCs proliferate and differentiate to mature DCs. The mature DCs interact with antigen specific $\mathrm{T}$ - and

Table I. Clinical and histological data of the patients with lung cancer $(\mathrm{n}=40)$

\begin{tabular}{|c|c|}
\hline PARAmeter & Number (\%) \\
\hline Clinical data & $(\mathrm{n}=40)$ \\
\hline \multicolumn{2}{|l|}{ Sex } \\
\hline Males & $37(92.5)$ \\
\hline Females & $3(7.5)$ \\
\hline \multicolumn{2}{|l|}{ Age (years) } \\
\hline median & 62.8 \\
\hline (range) & $(24-77)$ \\
\hline \multicolumn{2}{|l|}{ T stage } \\
\hline $\mathrm{T} 1-2$ & $6(15.0)$ \\
\hline T3-4 & $34(85.0)$ \\
\hline \multicolumn{2}{|l|}{$\mathrm{N}$ stage } \\
\hline No & $28(70.0)$ \\
\hline $\mathrm{N} 1-3$ & $12(30.0)$ \\
\hline \multicolumn{2}{|l|}{ Metastasis } \\
\hline None & $33(82.5)$ \\
\hline Present & $7(17.5)$ \\
\hline \multicolumn{2}{|l|}{ Clinical stage } \\
\hline I & $11(13.8)$ \\
\hline II & $10(12.5)$ \\
\hline III & $11(13.8)$ \\
\hline IV & $8(10.0)$ \\
\hline \multicolumn{2}{|l|}{ HistOLOGICAL DATA } \\
\hline \multicolumn{2}{|l|}{ Differentiation } \\
\hline Low & $20(50.0)$ \\
\hline Medium & $19(47.5)$ \\
\hline High & $1(2.5)$ \\
\hline \multicolumn{2}{|l|}{ Histological type } \\
\hline Adenocarcinoma & $15(37.5)$ \\
\hline Squamous cell carcinoma & $25(62.5)$ \\
\hline
\end{tabular}

B-lymphocytes in order to initiate adaptive immune response [9]. They phagotisize and process the material from the surrounding microenvironment. The phagotisized proteins are degraded to peptides and are presented to the MHC molecules (major histocompatibility complex). Dendritic cells are activated by different agents that damage the normal tissues like bacteria, viruses, apoptotic cells or cancer proteins.

The role of DC in the lung immunity is an object of investigations for a long time. Although these investigations, made on human DC associated with NSCLC are little. Two types of DC are found during these investigations: myeloid $\mathrm{DC}(\mathrm{mDC})$ and plasmacytoid DC (pDC) $\{10,11\}$. The localization and phenotype of the two subsets of DC are not fully understood.

In human models, DCs could be divided on several subpopulations according to their phenotypes and functions by expression of different markers. Two types of DC are described based on the expression of CD11c and CD123 (IL-3 receptor $\alpha$ chain) [9]. Typical mDC express $\mathrm{CD} 11 \mathrm{c}$ and do not express CD123, and are also potential inhibitors of Th1 mediated immune response [12]. On the other hand, CD11c negative DC are defined as $\mathrm{pDC}$ which take place in regulation of Th2 mediated immune response and express CD123.

As part of the adhesion molecule integrin $\beta 2$ family, $\mathrm{CD} 11 \mathrm{c}$ is expressed by myeloid and monocyte-associated DC. CD11c is also found on the surface of macrophages, activated $\mathrm{T}$ and $\mathrm{B}$ lymphocytes, NK-cells [13]. Some studies prove the association between degree of infiltration of tumors by DC and the prognosis of the disease. In general, the infiltration with mature DC defines better prognosis, while the infiltration with immature DCs with poor prognosis [14, 15].

In our study we analyzed the significance of CD $11 \mathrm{c}$ and $\mathrm{CD} 123$ positive DCs and their relationship with some clinical and pathologic parameters of patients with NSCLC.

\section{Material and methods}

Biopsy materials taken from 40 patients undergoing pulmonary resection at the Clinic of Thoracic Surgery of the University Hospital - Stara Zagora between 2007 and 2017 were studied. The group consists of 37 men and 3 women, aged between 24 and 77 years (average age 62.8 years). Retrospectively, clinical and histological data were collected for the patients presented in Table I.

\section{Immunohistochemistry}

Lung cancer tissues from all 40 patients were analysed immunohistochemically. Specimens were fixed in $10 \%$ buffered formalin, embedded in paraffin and then cut to $4 \mu \mathrm{m}$ thickness. Next step were dewaxed and endogenous peroxidase was blocked for 5 minutes with blocking reagent according to the protocol. 
Then the slides were washed 3 times with PBS and incubated with primary antibody for 1 hour. After that slides washing 3 times the slides were incubated with marked polymer and then washed again. In the last phase they were incubated with DAB substratechromogen and were washed again. At the end they were contrastained with Mayer's hematoxylin.

Immunohistochemical reaction were carried out using Mouse Monoclonal Antibody CD11c (NCL-LCD11c-563, Novocastra) in a dilution 1:100 and Mouse Monoclonal Antibody CD123 (NCL-L-CD123, Novocastra) in a dilution 1:100, as well as detection system EnVision ${ }^{\mathrm{TM}}$ FLEX +, Mouse, High pH, (Link) (K8002, DAKO). The analysis was performed according to the manufacturer's protocols. Two pathologists evaluated immunohistochemical results (J.A. and M.G.).

\section{Cell counting}

CD11c- and CD123-positive cells were counted in the tumour stroma and at the tumour border, on five fields of vision in the areas with most intensive cell recruitment (hot spots) at a magnification $(\times 320$, $0.74 \mathrm{~mm}^{2}$ area). The number of the positive cells was calculated at $1 \mathrm{~mm}^{2}$ area.

\section{Statistical analysis}

Survey data was statistically processed using SPSS for Windows Version 16 (SPSS, Inc., Chicago, IL, USA). Nonparametric analyzes were applied - the Mann-Whitney U test and the Wilcoxon Signed rank test. A $\chi^{2}$ test was used to compare the frequency of distribution of the test parameters. In all analyzes, results having a level of significance $\mathrm{p}<0.05$ were considered statistically reliable.

\section{Results}

After the immunohistochemical examination of the NSCLC cases, we performed an analysis comparing the distribution and density of the cells in the respective locations, as well as their relationship with the various clinical and morphological indicators.

\section{Localization and frequency of DC expressing CD11c and CD123}

The analysis of all 40 cases revealed an uneven distribution of the two CD11c- and CD123-positive DC populations studied in the tumour stroma and the tumour border. CD11c-tumor-infiltrating DC (TIDC) are diffusively distributed in the tumour stroma and border (Fig. 1A, B), but we did not find a statistically significant difference in their density in the two localizations, but there is still a visible tendency for them to reach the limit $(53.9 \pm 8.9$ vs. $69.8 \pm 11.4, \mathrm{p}=0.073)$. A similar result, again without a significant difference, was also observed with respect to the distribution of
CD123-labeled CD123 in the stroma and border $(5.67$ \pm 8.3 vs. $6.91 \pm 10.9, p=0.209$; Fig. $1 C, D$ ). We also found that the CD123 TIDC in the stroma and at the border with the surrounding tissue were fewer than the CD11c-positive DC in the same sites $(5.67 \pm 8.3$ vs. $53.9 \pm 8.9, \mathrm{p}=0.001$, respectively $6.91 \pm 10.9$ vs. $69.8 \pm 11.4, \mathrm{p}<0.001$; Table II).

\section{Correlation between DC and clinical- morphological data}

We analyzed the correlations between TIDC and clinical-morphological indicators. For this purpose, the patients were divided into three groups: low and high infiltration of DC in the tumour stroma and border. A statistically significant association was found between the number of CD11c in the tumour stroma and the tumour size, as well as between the infiltration with CD123-positive TIDC in the tumour stroma and the border and the presence of metastases in the lymph nodes and distant metastases as well as the tumour stage.

In $35.3 \%$ of the patients in the T3-4 tumour stage had a high CD11c infiltration in the tumour stroma, while $100 \%$ of the patients in the T1-2 tumour stage had low infiltration $\left(\chi^{2}=4.72, p=0.03\right)$.

Comparing the density of CD123-positive DCs in the tumour border of patients and lymph node involvement, we found that $58.3 \%$ of patients without lymph node involvement had low infiltration with CD123-positive TIDC, whereas in patients with metastatic lymph nodes that percentage was $92.9 \%$ $\left(\chi^{2}=6.94, p=0.008\right)$. We also found that $15.2 \%$ of patients in the M1 stage had a high infiltration with CD123 in the tumour stroma, whereas only $71.4 \%$ of patients without metastases had high infiltration, analogous data are also found in comparing the distribution of CD123 in the tumour border $\left(\chi^{2}=9.76, p=0.002\right.$ or $\left.\chi^{2}=9.24, p=0.002\right)$. However, $4.55 \%$ of the patients in I-II clinical stage, had high infiltration with CD123-positive DCs vs. $33.3 \%$ of patients in III and IV stage $\left(\chi^{2}=5.49\right.$; $\mathrm{p}=0.019)$. No other significant differences were found in comparison of the distribution of the cells and the indicators (Table III).

\section{Discussion}

The data from our study indicates early stage of disease, observed in tumors stroma infiltrated by CD11c positive cells, and tumour progression when CD11c positive cells infiltrate the tumour border. In addition our data shown relation between tumour progression in cases having higher infiltration of CD123 cells in the stroma. Similar conclusions have been made in studies that investigated the impact of infiltration with DC in other types of cancers: colorectal, NSCLC, melanoma, gastric cancer $[14,15,16,17]$. 

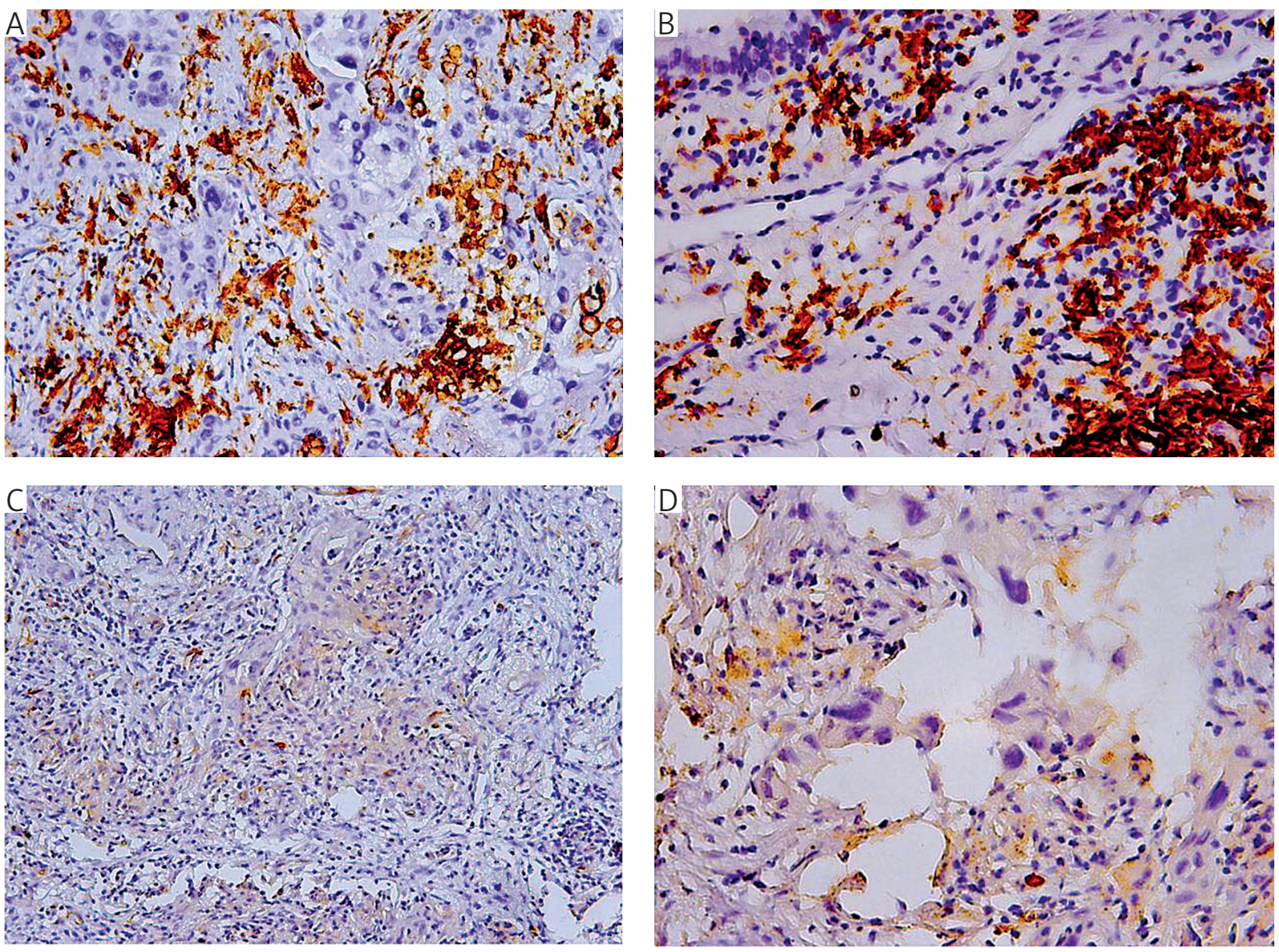

Fig. 1. A) CD11c-positive DCs in tumour stroma (200×). B) CD11c-positive DCs in tumour border (400×). C) CD123positive DCs in tumour stroma $(200 \times)$. D) CD123-positive DCs in tumour border $(400 \times)$

Table II. Density $($ cells/mm²) of CD11c-positive and CD123-positive DC in NSCLC in the tumour and in the tumour border

\begin{tabular}{lccc}
\hline Cell type and location & CD11C & CD123 & Wilcoxon Signed RANK \\
\hline Tumor & & & \\
\hline Mean \pm SD & $53.9 \pm 8.9$ & $5.67 \pm 8.3$ & CD11c vs. CD123 \\
\hline Median & 37.4 & 2.25 & $\mathrm{p}=0.001$ \\
\hline (range) & $3.6-346.8$ & $0.01-44.1$ & \\
\hline Tumor border & & & \\
\hline Mean \pm SD & $69.8 \pm 11.4$ & $6.91 \pm 10.9$ & CD11c vs. CD123 \\
\hline Median & 45.0 & 1.8 & \\
\hline (range) & $0.01-259.5$ & $0.01-53.1$ & \\
\hline Mann-Whitney U test & $\begin{array}{c}\text { Tumour vs. border } \\
\mathrm{p}=0.073\end{array}$ & $\begin{array}{c}\text { Tumour vs. border } \\
\mathrm{p}=0.209\end{array}$ \\
\hline
\end{tabular}

Dendritic cells are the main actors of the anti-tumour immunity. After maturation, the DC migrate into the lymph nodes, where they present the peptides to the T-cells with collaboration of the MHC molecules. The recognition of the MHC-peptide complex and stimulation from other activating molecules and cyto- kines, secreted by the DC, leads to activation of effector T- cells. DC, which are not activated form such signals or are influenced by inhibitory signals (such as corticosteroids or IL-10) are responsible for development of immune tolerance by miss to activate the T-cells or by activation of T-regs. Thus, depending on their po- 
Table III. Correlation between CD11c- and CD123-positive DC into the tumour stroma and tumour border, and clinical and morphological factors

\begin{tabular}{|c|c|c|c|c|c|c|c|c|c|c|c|c|}
\hline & \multicolumn{6}{|c|}{$\mathrm{CD} 11 \mathrm{C}$} & \multicolumn{6}{|c|}{ CD123 } \\
\hline & \multicolumn{3}{|c|}{ Tumour } & \multicolumn{3}{|c|}{ BORDER } & \multicolumn{3}{|c|}{ Tumour } & \multicolumn{3}{|c|}{ BORDER } \\
\hline & Low & HiGH & $P$ & Low & HiGH & $P$ & Low & HigH & $P$ & Low & HigH & $P$ \\
\hline \multicolumn{13}{|l|}{ Tumor } \\
\hline $\mathrm{T} 1-2$ & 3 & 3 & NS & 6 & 0 & $p=0.03$ & 5 & 1 & NS & 6 & 0 & NS \\
\hline T3-4 & 24 & 10 & & 22 & 12 & & 25 & 9 & & 27 & 7 & \\
\hline \multicolumn{13}{|l|}{$\begin{array}{l}\text { Engaged } \\
\text { lymph nodes }\end{array}$} \\
\hline Present & 18 & 10 & NS & 19 & 9 & NS & 22 & 6 & NS & 26 & 2 & $\mathrm{p}=0.008$ \\
\hline Absent & 9 & 3 & & 9 & 3 & & 8 & 4 & & 7 & 5 & \\
\hline \multicolumn{13}{|l|}{ Metastasis } \\
\hline Present & 22 & 11 & NS & 23 & 10 & NS & 28 & 5 & $\mathrm{p}=0.002$ & 30 & 3 & $\mathrm{p}=0.002$ \\
\hline Absent & 5 & 2 & & 5 & 2 & & 2 & 5 & & 3 & 4 & \\
\hline \multicolumn{13}{|l|}{ Clinical stage } \\
\hline I-II & 12 & 8 & NS & 15 & 5 & NS & 19 & 3 & NS & 21 & 1 & $\mathrm{p}=0.019$ \\
\hline III-IV & 14 & 3 & & 11 & 9 & & 11 & 7 & & 12 & 6 & \\
\hline \multicolumn{13}{|l|}{ Differentiation } \\
\hline Low & 12 & 8 & NS & 12 & 6 & NS & 13 & 5 & NS & 15 & 3 & NS \\
\hline Medium & 14 & 5 & & 14 & 7 & & 14 & 5 & & 15 & 4 & \\
\hline high & 1 & 0 & & 1 & 0 & & 1 & 2 & & 1 & 2 & \\
\hline \multicolumn{13}{|l|}{ Histological type } \\
\hline Adenocarcinoma & 9 & 6 & NS & 9 & 6 & NS & 12 & 2 & NS & 12 & 2 & NS \\
\hline $\begin{array}{l}\text { Squamous cell } \\
\text { carcinoma }\end{array}$ & 18 & 7 & & 18 & 7 & & 17 & 9 & & 20 & 6 & \\
\hline
\end{tabular}

larization the tumour infiltrating antigen-presenting cells demonstrate different characteristics, which are typical for anti-tumour or pro tumourigenic immune response. $\mathrm{CD} 11 \mathrm{c}$ is a component of the complement receptor 4, which is predominantly expressed on DC, but also on some macrophages, NK-cells and activated T-cells [18, 19, 20].

According this information, the degree of infiltration with $\mathrm{CD} 11 \mathrm{c}$ is determined also by these specific cells. Some data show that CD11c positive DC activate CD4 T-cells, but CD11c is found also on the surface of some CD8 T-cell [21]. These CD11c positive CD8 T-cells usually suppress CD4 T-cells but in some cases they have opposite function as effectors. It is more interesting that in both cases their presence is positive for the patients and they contribute to augmentation of the anti-tumour potential of the microenvironment [22, 23].

At present, there are very few studies associating the extent of CD11c expression in the tumour microenvironment and tumour progression. On the other hand, CD123-positive cells are definitely immature. At present, the studies investigating the degree of infiltration of the tumors with CD123 and the influence of this prognosis to prognosis or stage of disease are very few.

CD123 is a typical marker for pDC, although some CD123 positive mDC are described. The CD123 positive $\mathrm{mDC}$ are derived from blood monocytes and are actually immature [24, 25]. The CD123-positive cells in LC are considered to be endothelial cells, because they also express CD31, which is a marker for endothelial cells. Despite this data, the authors describe a population of DC that migrate to the endothelium and express markers for both endothelial and dendritic cells. Having this in mind the cells in our investigation could be considered as DC.

The activated pDC are also known as producers of interferons. The $\mathrm{pDC}$ in tumors are presented by their inactive forms that are thought to be responsible for the maintaining suppressive immune microenvironment trough activating T-regs $[26,27]$. These mechanisms are probably responsible for the association of worse prognosis in different neoplasms with high degree infiltration with DCs, and especially CD123- and CD207-positive cells. These correlations are observed 
in melanoma, when the infiltration is higher in different parts of the tumour $[28,29]$. The infiltration with CD123-positive cells as bad predictor is also described in breast cancer, where the high degree of infiltration is an in dependent prognostic factor for determining survival and prognosis $[30,31]$. Similar constellation is found in myelogenous leukemia [32]. This data shows that the tumour infiltrating $\mathrm{pDC}$ are found as negative prognostic marker in some types of cancer [33, 34$]$.

In conclusion our results indicate that the infiltration with $\mathrm{mDCs}$ and $\mathrm{pDCs}$ is related with some characteristics of NSCLC and this infiltration is related with tumour progression, suggesting a central role for DCs population in antitumour immunity.

\section{The authors declare no conflict of interest.}

\section{References}

1. Siegel RL, Miller KD, Jemal A. Cancer Statistics, 2017. CA Cancer J Clin 2017; 67: 7-30.

2. Gabrilovich D. Mechanisms and functional significance of tumour-induced dendritic-cell defects. Nat Rev Immunol 2004; 4: 941-952.

3. Hanahan D, Weinberg RA. The hallmarks of cancer. Cell 2000; 100: 57-70.

4. Hanahan D, Weinberg RA. Hallmarks of cancer: the next generation. Cell 2011; 144: 646-674.

5. Dunn GP, Old LJ, Schreiber RD. The three Es of cancer immunoediting. Annu Rev Immunol 2004; 22: 329-360.

6. Zitvogel L, Tesniere A, Kroemer G. Cancer despite immunosurveillance: immunoselection and immunosubversion. Nat Rev Immunol 2006; 6: 715-727.

7. Talmadge JE, Donkor M, Scholar E. Inflammatory cell infiltration of tumors: Jekyll or Hyde. Cancer Metastasis Rev 2007; 26: 373-400.

8. Pagès F, Kirilovsky A, Mlecnik B, et al. In situ cytotoxic and memory $\mathrm{T}$ cells predict outcome in patients with early-stage colorectal cancer. J Clin Oncol 2009; 27: 5944-5951.

9. Banchereau J, Steinman RM. Dendritic cells and the control of immunity. Nature 1998; 392: 245-252.

10. Grouard G, Rissoan MC, Filgueira L, et al. The enigmatic plasmacytoid $\mathrm{T}$ cells develop into dendritic cells with interleukin (IL)-3 and CD40-ligand. J Exp Med 1997; 185: 1101-1111.

11. Inaba $\mathrm{K}$, Inaba $\mathrm{M}$, Deguchi $\mathrm{M}$, et al. Granulocytes, macrophages, and dendritic cells arise from a common major histocompatibility complex class II-negative progenitor in mouse bone marrow. Proc Natl Acad Sci U S A 1993; 90: 3038-3042.

12. Rissoan MC, Soumelis V, Kadowaki N, et al. Reciprocal control of T helper cell and dendritic cell differentiation. Science 1999; 283: 1183-1186.

13. Castro FV, Tutt AL, White AL, et al. CD11c provides an effective immunotarget for the generation of both CD4 and CD8 T cell responses. Eur J Immunol 2008; 38: 2263-2273.

14. Gulubova MV, Ananiev JR, Vlaykova TI, et al. Role of dendritic cells in progression and clinical outcome of colon cancer. Int J Colorectal Dis 2012; 27: 159-169.

15. Sandel MH, Dadabayev AR, Menon AG, et al. Prognostic value of tumor-infiltrating dendritic cells in colorectal cancer: role of maturation status and intratumoral localization. Clin Cancer Res 2005; 11: 2576-2582.

16. Al-Shibli K, Al-Saad S, Donnem T, et al. The prognostic value of intraepithelial and stromal innate immune system cells in nonsmall cell lung carcinoma. Histopathology 2009; 55: 301-312.
17. Mahmoud SM, Lee AH, Paish EC, et al. Tumour-infiltrating macrophages and clinical outcome in breast cancer. $\mathrm{J}$ Clin Pathol 2012; 65: 159-163.

18. Cooney LA, Gupta M, Thomas S, et al. Short-lived effector CD8 $\mathrm{T}$ cells induced by genetically attenuated malaria parasite vaccination express CD11c. Infect Immun 2013; 81: 4171-4181.

19. Chan CW, Crafton E, Fan HN, et al. Interferon-producing killer dendritic cells provide a link between innate and adaptive immunity. Nat Med 2006; 12: 207-213.

20. Caminschi I, Ahmet F, Heger K, et al. Putative IKDCs are functionally and developmentally similar to natural killer cells, but not to dendritic cells. J Exp Med 2007; 204: 2579-2590.

21. Fahlén-Yrlid L, Gustafsson T, Westlund J, et al. CD11c (high) dendritic cells are essential for activation of $\mathrm{CD} 4+\mathrm{T}$ cells and generation of specific antibodies following mucosal immunization. J Immunol 2009; 183: 5032-5041.

22. Choi BK, Kim YH, Kang WJ, et al. Mechanisms involved in synergistic anticancer immunity of anti-4-1BB and anti-CD4 therapy. Cancer Res 2007; 67: 8891-8899.

23. Vinay DS, Kwon BS. CD11c+CD8+ T cells: two-faced adaptive immune regulators. Cell Immunol 2010; 264: 18-22.

24. Ward KA, Stewart LA, Schwarer AP. CD34+-derived $\mathrm{CD} 11 \mathrm{c}+++\mathrm{BDCA}-1++\mathrm{CD} 123++\mathrm{DC}$ : expansion of a phenotypically undescribed myeloid DC1 population for use in adoptive immunotherapy. Cytotherapy 2006; 8: 130-140.

25. Shi J, Ikeda K, Maeda Y, et al. Identification of CD123+ myeloid dendritic cells as an early-stage immature subset with strong tumoristatic potential. Cancer Lett 2008; 270: 19-29.

26. Chaput N, Conforti R, Viaud S, et al. The Janus face of dendritic cells in cancer. Oncogene 2008; 27: 5920-5931.

27. Lande R, Gilliet M. Plasmacytoid dendritic cells: key players in the initiation and regulation of immune responses. Ann N Y Acad Sci 2010; 1183: 89-103.

28. Jensen TO, Schmidt H, Møller HJ, et al. Intratumoral neutrophils and plasmacytoid dendritic cells indicate poor prognosis and are associated with pSTAT3 expression in AJCC stage I/II melanoma. Cancer 2012; 118: 2476-2485.

29. Dyduch G, Tyrak KE, Glajcar A, et al. CD207+/langerin positive dendritic cells in invasive and in situ cutaneous malignant melanoma. Postepy Dermatol Alergol 2017; 34: 233-239.

30. Treilleux I, Blay JY, Bendriss-Vermare N, et al. Dendritic cell infiltration and prognosis of early stage breast cancer. Clin Cancer Res 2004; 10: 7466-7474

31. Sisirak V, Faget J, Gobert M, et al. Impaired IFN- $\alpha$ production by plasmacytoid dendritic cells favors regulatory T-cell expansion that may contribute to breast cancer progression. Cancer Res 2012; 72: 5188-5197.

32. Liu W, Ye SY, Lei L. Clinical significance of CD123 expression and FTL3-ITD mutation in acute myeloid leukemia. Proc Clin Med 2013; 6: 408-410.

33. Vermi W, Bonecchi R, Facchetti F, et al. Recruitment of immature plasmacytoid dendritic cells (plasmacytoid monocytes) and myeloid dendritic cells in primary cutaneous melanomas. J Pathol 2003; 200: 255-268.

34. Mohty M, Olive D, Gaugler B. Plasmacytoid DCs and cancer: a new role for an enigmatic cell. Trends Immunol 2004; 25: 397-398.

\section{Address for correspondence}

\section{Julian Ananiev, PhD, MD}

Trakia University, Medical Faculty

Department of General and Clinical Pathology

11 Armeiska Str.

6000 Stara Zagora, Bulgaria

e-mail: operation@abv.bg, julian.r.ananiev@gmail.com 